\title{
Effect of hot calendering on physical properties and water vapor transfer resistance of bacterial cellulose films
}

\author{
V. L. D. Costa $^{1}$, A. P. Costa ${ }^{1,2}$, M. E. Amaral ${ }^{1,2}$, C. Oliveira ${ }^{3}$, M. Gama ${ }^{3}$, F. Dourado ${ }^{3}$, and R. M. Simões ${ }^{1,2, *}$ \\ ${ }^{1}$ Research Unit of Fiber Materials and Environmental Technologies (FibEnTech - UBI), Universidade da Beira Interior, Rua Marquês \\ d'Avila e Bolama, 6201-001 Covilhã, Portugal \\ ${ }^{2}$ Department of Chemistry, Universidade da Beira Interior, 6201-001 Covilhã, Portugal \\ ${ }^{3}$ CEB-Centre of Biological Engineering, University of Minho, 4710-057 Braga, Portugal
}

Received: 23 March 2016

Accepted: 2 June 2016

Published online:

27 July 2016

(C) Springer Science+Business

Media New York 2016

\begin{abstract}
This work investigates the effect of hot calendering on bacterial cellulose (BC) films properties, aiming the achievement of good transparency and barrier property. A comparison was made using vegetal cellulose (VC) films on a similar basis weight of around $40 \mathrm{~g} . \mathrm{m}^{-2}$. The optical-structural, mechanical, and barrier properties of $B C$ films were studied and compared with those of highly beaten VC films. The Young's moduli and tensile index of the BC films are much higher than those obtained for VC (14.5-16.2 vs 10.8-8.7 GPa and 146.7-64.8 vs 82.8-40.3 N.m.g ${ }^{-1}$ ), respectively. Calendering increased significantly the transparency of BC films from 53.0 to $73.0 \%$. The effect of BC ozonation was also studied. Oxidation with ozone somewhat enhanced the brightness and transparency of the BC films, but at the expenses of slightly lower mechanical properties. BC films exhibited a low water vapor transfer rate, when compared to VC films and this property decreased by around $70 \%$ following calendering, for all films tested. These results show that calendering could be used as a process to obtain films suitable for food packaging applications, where transparency, good mechanical performance, and barrier properties are important. The BC films obtained herein are valuable products that could be a good alternative to the highly used plastics in this industry.
\end{abstract}

\section{Introduction}

Cellulose is a bio-based natural polymer, the most abundant polysaccharide in nature. Cellulose is extensively synthesized by plants, but it can also be produced by bacteria and tunicates [1]. Bacterial cellulose $(B C)$ is mainly produced by gram-negative bacteria like Gluconacetobacter xylinus, Gluconacetobacter sucrofermentans. Using the appropriate growth conditions, these bacteria produce cellulose as a

Address correspondence to E-mail: rmss@ubi.pt 
primary metabolic product in which the extracellular cellulose nanofibrils (of less than $10 \mathrm{~nm}$ width) form a three-dimensional highly hydrated network gel. BC is chemically identical to that produced by plants but has unique physical and chemical properties, i.e., high crystallinity, surface area, degree of polymerization $\left(\mathrm{DP}_{\mathrm{v}}\right)$, mechanical strength, and purity $[2,3]$. In addition, the $\mathrm{BC}$ properties depend on the used strain and culture parameters [4]. Unlike the cellulose from wood pulp, BC is free of other contaminating polysaccharides and its isolation and purification are relatively simple, not requiring energy or chemically intensive processes. In addition, the release of cellulose nanofibrils from vegetal fibers can require up to $30,000 \mathrm{kWh} \cdot \mathrm{ton}^{-1}$ [5]. Furthermore, the production of vegetal fibers from wood has environmental impacts. These aspects give an added impetus to the study of alternative sources of cellulose [6].

Due to the mentioned properties, BC has a wide field of applications including biomedical, such as artificial skin [7] and tissue regeneration [8], or as a reinforcing agent for the design of nanocomposites [9]. In the field of paper restoration, Santos et al. [4] reported that the use of $\mathrm{BC}$ could be more suitable than the currently used Japanese Paper. On the other hand, the combination of BC with recycled paper fibers, for example, has proven to be an efficient technique to improve the mechanical properties of the final product [10-12]. Fragmented BC has also promising prospects in papermaking due to flexural behavior and durability, among other characteristics $[10,13]$. In the paper and board industry, there are several products where it might be used in order to improve the physical-mechanical properties of the final product [14]. Furthermore, BC can be modified with cellulose-binding modules to refine these properties and/or introduce bioactive features [15]. In opposition to paper materials, where opacity is a key property in most applications (i.e., printing and writing papers), in films for application in food packaging and other uses, transparency is looked for. Nowadays, the most used films are the affordable polyethylene and polypropylene, which exhibit good transparency and barrier properties for water and oxygen, but are hardly recyclable and produced from oil. On the contrary, cellulose-based materials are renewable, recyclable and therefore have potential to contribute to a sustainable green economy [16]. The potential of nanocellulose to produce films with good levels of transparency is reported by some authors
$[17,18]$. Several strategies have been explored to improve transparency, namely wet press, while calendering has never been explored so far. Calendering is a thermo-mechanical treatment where the material is passed between several pairs of heated rollers [19]. When applied to paper materials, calendering increases the transparency [20]. To the best of our knowledge, the effect of hot calendering operation on $\mathrm{BC}$ films properties has not been yet studied. Here, BC films were produced from $\mathrm{BC}$ suspensions using a process similar to papermaking. The behavior of the produced BC films and the effect of calendering on the mechanical, optical-structural, and water vapor transfer rate (WVTR) were studied and compared with VC films processed in a similar way. The effect of BC ozonation (BCO) on brightness and transparency was also studied.

\section{Materials and methods}

\section{Production of bacterial cellulose}

Gluconacetobacter xylinus (ATCC 53582) was maintained in solid Hestrin-Schramm culture medium (HS) [21] using $2 \%$ (w/v) agar (HiMedia). BC fermentation was done under static culture conditions, using HS at $30{ }^{\circ} \mathrm{C}$ for at least four weeks. The composition (in $\mathrm{w} / \mathrm{v}$ ) of the HS medium is as follows: $2 \%$ glucose (Sigma-Aldrich), $0.5 \%$ peptone (SigmaAldrich), $0.5 \%$ yeast extract (HiMedia), $0.34 \% \mathrm{Na}_{2}$ $\mathrm{HPO}_{4} \cdot 2 \mathrm{H}_{2} \mathrm{O}$ (Sigma-Aldrich), $0.15 \%$ citric acid (Pronolab). The final $\mathrm{pH}$ was adjusted to 5.5 using $\mathrm{HCl} 18 \%$ (v/v) (Sigma-Aldrich). The resulting BC membrane was extensively washed at room temperature with tap water, to remove residual culture medium; afterward it was placed in excess $1.0 \mathrm{~N}$ $\mathrm{NaOH}$ solution for $24 \mathrm{~h}$, to remove bacteria. The membrane was then washed thoroughly with distilled water until the final $\mathrm{pH}$ of the supernatant became that of distilled water, resulting in a whitish pellicle.

\section{Production of bacterial cellulose films}

The produced $\mathrm{BC}$ membranes were fragmented in a laboratory blender for $3 \mathrm{~min}$, after adding water until a solid content of $0.354 \%(\mathrm{w} / \mathrm{w})$, so as to produce a $\mathrm{BC}$ suspension. 
In order to improve the films brightness and evaluate the effect of oxidation on the carbonyl and carboxyl content and consequently on cellulose nanofibrils dispersion, a fraction of the BC suspension was submitted to ozonation (ozone produced from oxygen at a flow rate of 100 L.h ${ }^{-1}$, with an ozone concentration of $28 \mathrm{mg} . \mathrm{L}^{-1}$ ) during $15 \mathrm{~min}$, under vigorous agitation.

Films with a diameter of $98 \mathrm{~mm}$ were manufactured from ozonated (BCO) and non-ozonated suspensions (BC) with a basis weight of around $40 \mathrm{~g} \cdot \mathrm{m}^{-2}$, by vacuum filtration, using a filter paper as filtration medium (FiltresRS). After the water had been drained, the upper side of BC sheets was adhered to metallic discs with the same diameter. Thereafter, a stacking of disc, BC sheet, filter paper, and blotting paper, was prepared for pressing at 1.45 MPa for $5 \mathrm{~min}$, using a procedure similar to paper production (SCAN-CM 64:00). Then, the filter papers were carefully removed and the BC films were dried overnight, adhered to the metallic discs, between perforated metallic rings under a small pressure applied to the edge of the sheets in order to prevent the films from shrinking, in a standard atmosphere for conditioning $\left(23^{\circ} \mathrm{C}\right.$ and $50 \%$ of relative humidity) according to ISO 187:1990. From each material (BC and $\mathrm{BCO}$ ) sixteen films were produced.

\section{Production of vegetal cellulose films}

An eucalypt bleached kraft pulp was beaten to $80^{\circ}$ Schopper Riegler ( $\left.{ }^{\circ} \mathrm{SR}\right)$, using a Valley beater. The VC films were produced from this highly beaten pulp, according to standard procedure ISO 5269-1:2005. The film's basis weight was approximately 40 g.m $\mathrm{m}^{-2}$.

\section{Intrinsic viscosity and degree of polymerization}

In order to evaluate the possible cellulose depolymerisation in the ozone treatment, the intrinsic viscosity of the $\mathrm{BC} / \mathrm{BCO}$ and $\mathrm{VC}$, in the form of films, was measured after dissolution in a cupriethylenediamine (CED) solution (SCAN-CM 15:99). The DP ${ }_{\mathrm{v}}$ was calculated from viscosity [22].

\section{Calendering of the films}

The films produced from each type of BC suspension were divided into four sets, each containing four films; one set was not calendered, and the remaining three were submitted to calendering with two metal rolls on a hard calender (HC) (Beloit Wheeler- Model 703) using a linear pressure of $120 \mathrm{kN} \cdot \mathrm{m}^{-1}$ at a fixed temperature of $100{ }^{\circ} \mathrm{C}$. The samples were passed 1,3 , or 6 times between the calender roller pair, which will be mentioned as BC_HCX, where $X$ is the number of passes between the roller pair. A similar procedure was followed for the VC films.

\section{Characterization of the films}

Non-calendered and calendered $\mathrm{BC} / \mathrm{BCO}$ and $\mathrm{VC}$ films were characterized for their mechanical and optical-structural properties according to the appropriate ISO standards for cellulosic materials, mentioned throughout the procedures and through the determination of the WVTR.

Structural and physical analysis of the films The morphological characterization of $\mathrm{BC} / \mathrm{BCO}$ and $\mathrm{VC}$ films was performed using scanning electron microscopy (SEM) (Hitachi S-2700, operated at $20 \mathrm{kV}$ ). All the samples were previously gold-covered by cathodic spraying.

The X-ray diffraction (XRD) technique was employed in order to determine the crystallinity index (Crl) of the samples. The XRD was carried out on a diffractometer DMAX-III/C (Rigaku), using a copper X-ray source. Scans were collected at $1.2^{\circ} \mathrm{min}^{-1}$ from 5 to $60^{\circ} 2 \theta$. The CrI was then calculated using the peak height method, according to Eq. (1) [23].

$\operatorname{CrI}(\%)=\frac{I_{200}-I_{\mathrm{am}}}{I_{200}} \times 100$

where $I_{200}$ is the overall intensity $2 \theta$ of the crystalline region at about $22.8^{\circ} ; I_{\mathrm{am}}$ is the overall intensity $2 \theta$ of the amorphous region at about $18^{\circ}$. The porosity $(\mathrm{P})$ of the different structures was estimated according to the Eq. (2),

$\mathrm{P}(\%)=100 \times\left(1-\frac{\rho_{\text {sample }}}{\rho_{\text {cellulose }}}\right)$

where $\rho_{\text {sample }}$ is the density of the sample, g.cm ${ }^{-3}$; $\rho_{\text {cellulose }}$ is the density of cellulose, which is assumed to be 1.6 g. $\mathrm{cm}^{-3}$ [24-26]. BC, BCO, and VC films characterization was performed before and after calendering. In all cases, the samples were tested according to ISO 187:1990. The basis weight was calculated according ISO 536:2012 and samples 
thickness was measured with a micrometer (Adamel \& Lhomargy, M120 series) and the average of four measurements was calculated (ISO 1974:2012). The apparent film density (g.cm ${ }^{-3}$ ) was calculated dividing the basis weight $\left(\mathrm{g} \cdot \mathrm{m}^{-2}\right)$ by the film thickness $(\mu \mathrm{m})$.

A spectrophotometer Technidyne Corp., Color Touch 2, Model ISO was used to obtain the optical properties: brightness (ISO 2470-1:2009) and transparency.

Tensile strength, elongation at break, and Young's modulus were determined using a crosshead motion machine (Thwing-Albert Co, EJA series) with a load cell of $100 \mathrm{~N}$ and a constant rate of elongation $\left(20 \mathrm{~mm} \cdot \mathrm{min}^{-1}\right)$, according to ISO 1924-2:2008. The distance between grips was $50 \mathrm{~mm}$. The dry zerospan tensile tests were performed with a Pulmac tester (Pulmac, TS-100 Troubleshooter), according to ISO 15361:2000. Static bending stiffness was performed by a bending tester (Lorentzen \& Wettre) at an angle of $25^{\circ}$ and a 50-mm distance, according to an adaptation made from ISO 5628:2012. For all tests, at least four representative specimens of each film set have been tested and the average values were reported.

The WVTR was determined for calendered (6 passes) and non-calendered $\mathrm{BC} / \mathrm{BCO}$ films and for VC films. The WVTR was determined in home-made recipients, ensuring constant water vapor partial pressures in the both sides of the films throughout the essays. The interior of the recipients contained a given amount of anhydrous calcium chloride (SigmaAldrich) that ensured zero water partial vapor pressure inside the recipients. The other side of the film was in contact with standard conditions of temperature and humidity. The amount of water vapor that diffused through the films was accounted by the mass increase of the whole set, including recipient containing the calcium chloride. The whole sets were periodically weighted for $144 \mathrm{~h}$ and the mass gain was used to determine the WVTR of each sample, according to TAPPI $448 \mathrm{om}-09$. For each test, at least two films were used, and the arithmetic mean of the results was calculated.

\section{Results}

Aiming to increase the brightness of the films, BC suspension was treated with ozone, an environment friendly bleaching agent used in the bleaching of vegetal pulp fibers. Due to the relatively low selectivity of ozone, carbonyl groups are introduced in the cellulose chain, which can lead to cellulose depolymerization [27]. In fact, Table 1 shows that after ozone treatment, $\mathrm{BCO}$ exhibits $10 \%$ lower $\mathrm{DP}_{\mathrm{v}}$ (41.7\% lower intrinsic viscosity) than that of the untreated BC. Most of this depolymerization is likely to take place in the intrinsic viscosity determination process itself, since the carbonyl groups introduced in the cellulose chain may lead to its cleavage under the alkaline conditions used in the essay [27]. Calendering at $100{ }^{\circ} \mathrm{C}$ had a marginal effect on the DP of $\mathrm{BC}, \mathrm{BCO}$, and VC films. The intrinsic viscosity values obtained for the $B C$ are within the value range reported by Tsouko et al. [28] for disintegrated BC. The disintegration process carried out before the film formation also had a significant effect on the BC intrinsic viscosity; actually, the value decreased from $850 \mathrm{~mL} \cdot \mathrm{g}^{-1}$ (non-disintegrated) to $735 \mathrm{~mL} \cdot \mathrm{g}^{-1}$ (Table 1). The pulp fibers exhibit a slightly lower intrinsic viscosity than expected for an unbeaten pulp [29]. This value can be due to the intense beating that the vegetal fibers were submitted to produce the VC film.

BC films with a basis weight of around 40 g.m $\mathrm{m}^{-2}$ were produced by vacuum filtration, from the different cellulose suspensions. The physical properties of the produced films were characterized through several essays. The structural, mechanical, and optical properties of the calendered $(1,3$, and 6 passes between calender roller pair) and non-calendered films are shown in Table 2. The calendering process enables the production of vegetal and BC films with very low internal porosity and consequently with apparent densities close to the cellulose itself $\left(1.6 \mathrm{~g} . \mathrm{cm}^{-3}\right)$. As expected, the non-calendered films densities for $\mathrm{VC}$ and $\mathrm{BC}$ are different $(0.84$ versus $\left.1.13 \mathrm{~g} . \mathrm{cm}^{-3}\right)$, as a natural consequence of the

Table 1 Intrinsic viscosity and $\mathrm{DP}_{\mathrm{v}}$ of calendered (HC1 1 pass) and non-calendered $\mathrm{BC} / \mathrm{BCO}$ and $\mathrm{VC}$ films

\begin{tabular}{|c|c|c|}
\hline Sample & Intrinsic viscosity $\left(\mathrm{mL} \cdot \mathrm{g}^{-1}\right)$ & $\mathrm{DP}_{\mathrm{v}}^{\mathrm{a}}$ \\
\hline VC & 579 & 3792 \\
\hline VC_HC1 & 573 & 3784 \\
\hline $\mathrm{BC}$ & 735 & 3972 \\
\hline BC_HC1 & 727 & 3963 \\
\hline $\mathrm{BCO}$ & 428 & 3565 \\
\hline $\mathrm{BCO} \mathrm{HC} 1$ & 422 & 3555 \\
\hline
\end{tabular}


Table 2 Mechanical and optical-structural properties of VC, BC, and BCO films non-calendered (0) and calendered (1, 3, and 6 passes).The coefficients of variation were below $5 \%$

\begin{tabular}{|c|c|c|c|c|c|c|c|c|c|c|c|c|}
\hline \multirow[t]{2}{*}{ Properties } & \multicolumn{4}{|c|}{ VC film } & \multicolumn{4}{|c|}{ BC film } & \multicolumn{4}{|c|}{ BCO film } \\
\hline & 0 & 1 & 3 & 6 & 0 & 1 & 3 & 6 & 0 & 1 & 3 & 6 \\
\hline Basis weight, g.m ${ }^{-2}$ & 43.2 & 42.9 & 43.5 & 42.7 & 45.1 & 44.4 & 45.1 & 45.6 & 44.5 & 44.3 & 44.8 & 43.2 \\
\hline Apparent density, g.cm ${ }^{-3}$ & 0.84 & 1.40 & 1.45 & 1.46 & 1.13 & 1.45 & 1.47 & 1.51 & 1.20 & 1.45 & 1.58 & 1.58 \\
\hline Porosity, \% & 47.5 & 12.5 & 9.38 & 8.98 & 29.6 & 9.29 & 7.99 & 5.44 & 24.9 & 9.18 & 1.47 & 1.17 \\
\hline Tensile index, N.m.g ${ }^{-1}$ & 82.8 & 40.5 & 40.3 & 40.7 & 146.7 & 64.8 & 67.8 & 70.2 & 152.1 & 65.8 & 56.2 & 52.95 \\
\hline Elongation, \% & 3.42 & 1.60 & 1.50 & 1.33 & 5.37 & 1.00 & 1.18 & 1.04 & 4.88 & 1.11 & 1.06 & 0.93 \\
\hline $\begin{array}{l}\text { Dry zero-span tensile index, } \\
\text { N.m.g } \mathrm{g}^{-1}\end{array}$ & 130.5 & 98.4 & 86.6 & 93.1 & 181.4 & 174.5 & 166.2 & 173.4 & 177.1 & 169.7 & 159.0 & 172.8 \\
\hline Young's modulus, $\mathrm{GP}_{\mathrm{a}}$ & 10.8 & 8.7 & 9.4 & 9.4 & 14.5 & 16.2 & 16.7 & 16.7 & 11.9 & 12.3 & 16.2 & 16.9 \\
\hline Young's modulus ${ }^{\mathrm{a}}, \mathrm{GP}_{\mathrm{a}}$ & 20.5 & 10.0 & 10.4 & 10.3 & 20.5 & 17.8 & 18.2 & 17.7 & 15.9 & 13.5 & 16.4 & 17.1 \\
\hline Bending stiffness, $\mathrm{mN}$ & 16.3 & 8.3 & 8.7 & 9.5 & 17.5 & 16.5 & 14.5 & 15.8 & 17.0 & 15.7 & 16.5 & 15.5 \\
\hline ISO Brightness, \% & 66.15 & 57.73 & 57.85 & 57.31 & 71.44 & 68.38 & 67.16 & 67.08 & 74.43 & 72.71 & 70.81 & 70.64 \\
\hline Transparency, \% & 49.60 & 63.67 & 65.05 & 64.82 & 53.03 & 67.28 & 72.39 & 73.03 & 54.87 & 69.35 & 73.49 & 75.21 \\
\hline
\end{tabular}

${ }^{\text {a }}$ Normalized by the cellulose density $\left(1.6 \mathrm{~g} . \mathrm{cm}^{-3}\right)$; Young's modulus ${ }^{a}=\frac{\text { Young } s \text { modulus } \times 1.6}{\text { Apparent density }}$

dimensions of the constitutive elements. VC fibers have an average width and length of $18 \mu \mathrm{m}$ and $1 \mathrm{~mm}$, respectively, whereas $\mathrm{BC}$ fibrils have an approximate width of $10 \mathrm{~nm}$, while their length varies due to its branching growth nature. The segmental length between branching points was estimated as 580-960 $\mu \mathrm{m}$ [10], although the effect of mechanical treatment on the effective length cannot be neglected. The effect of calendering on apparent density can be observed in Table 2. The most noticeable impact is for the first pass in the hard calender, however, an important enhancement in transparency can be achieved with additional passes for the $\mathrm{BC} / \mathrm{BCO}$, which is not the case for VC films. The BC film transparency increased from around 53 to $73 \%$ after 6 passes calendering, which confirms the expected positive effect of this unit operation. However, only a marginal improvement in the BC films transparency was observed between the 3rd and 6th passage. Ozone treatment was here applied to $\mathrm{BC}$, to evaluate if it would improve the brightness levels. Results from Table 2 show that indeed the brightness of the $\mathrm{BC}$ films increased with ozone treatment, without losing transparency. Regarding the mechanical properties, BC/BCO presents much higher mechanical resistances than the VC. Since physical properties greatly depend on the basis weight, some properties were normalized taking into account the basis weight or the apparent density.
Tensile index at break represents the load normalized with the specimen's width and basis weight. BC/ $\mathrm{BCO}$ tensile index almost doubled one of the $\mathrm{VC}$ films. However, tensile index values were reduced in all cases to about half after the first pass in the calender. Dry zero-span tensile index is similar to normal tensile index, but the distance between grips being zero in this case. Assuming that no slippage occurs between the grips and the testing material, this measure estimates the intrinsic resistance of the constitutive elements of the material, which seems to be much higher for $\mathrm{BC} / \mathrm{BCO}$ than for $\mathrm{VC}$ films. Calendering affects the two materials differently; the intrinsic VC fiber strength decreases with calendering, whereas it remains practically constant for the BC/BCO. Young's modulus and bending stiffness were also measured and are reported in Table 2. As the apparent density of the material changes with calendering, a normalized Young's modulus was also calculated, based on the maximum density that the materials can achieve $\left(1.6 \mathrm{~g} . \mathrm{cm}^{-3}\right)$, which is the density of the cellulose itself. Interestingly, the two sources of cellulose (BC and VC) exhibit the same value for the normalized Young's modulus (20.5 GPa).

Morphological characterization of the different films was carried out by SEM. Selected micrographs are shown in Fig. 1, highlighting the different morphological dimensions of the constitutive fibers. The 

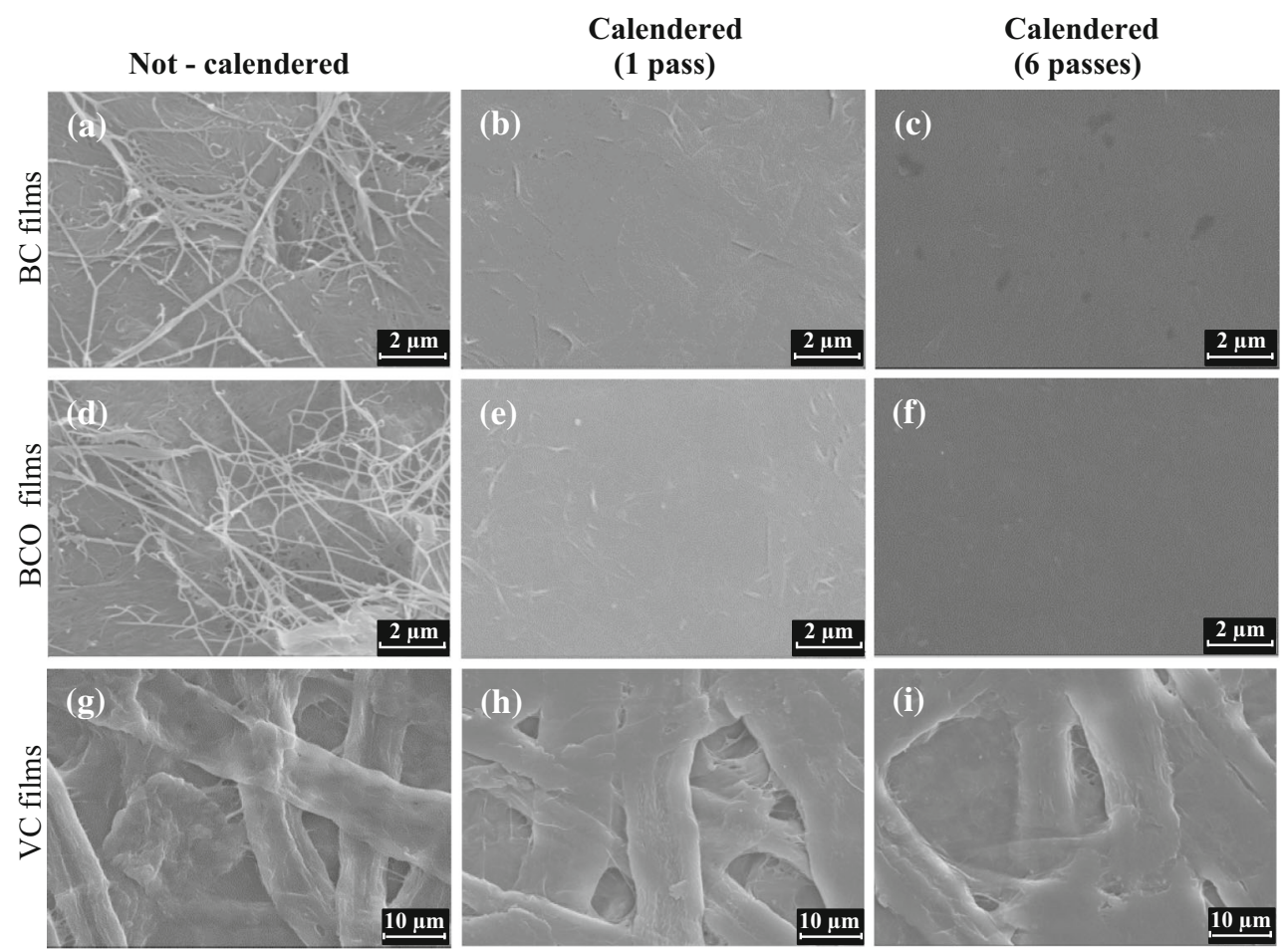

Figure 1 SEM images of the calendering effect on the BC/BCO films (magnification: $\times 10000$ ), and VC films (magnification: $\times 1500$ ). a, $\mathbf{d}, \mathbf{g}$ are non-calendered films, $\mathbf{b}, \mathbf{e}, \mathbf{h}$ are calendered films (1 pass) and $\mathbf{c}, \mathbf{f}, \mathbf{i}$ are calendered films (6 passes).

surface characteristics of the network structures changed with calendering leading to compact structures which agrees well with the lower porosity results presented in Table 2 .

The X-ray diffraction technique was employed to determine the crystallinity $\mathrm{v}(\mathrm{CrI})$. BC exhibits a higher $\mathrm{CrI}$ than the VC fibers (90.0 vs $75.6 \%$ ). The vegetal pulp fibers are produced from wood by a chemical process and contain $19 \%$ of hemicelluloses (amorphous material), in addition to cellulose. Therefore, the differences observed for the two sources of cellulose are expected. No significant effect of calendering on the $\mathrm{CrI}$ for the three materials was observed. On the contrary, Retegi et al. [30] observed a positive impact of wet pressure (uncompressed vs wet compressed at $10 \mathrm{MPa}$ ) on the crystallinity of BC.

For food packaging applications, the water vapor permeability of the films is of critical importance. Figure 2 shows the obtained results for the accumulated water vapor transferred through the films for calendered (6 passes) and non-calendered $\mathrm{BC} / \mathrm{BCO}$ and VC films. The effect of calendering is notorious for the vegetal films, whereas it is moderate for the BC. These results are consistent with the porosity of the different structures under evaluation (Table 2).
Table 3 resumes the effect of calendering on the WVTR for the different materials, where the much lower WVTR of the BC is evident when compared with the highly beaten VC film. In addition, the results show that the calendering process causes a decrease of around $70 \%$ in the WVTR for all samples. To facilitate the analysis, the global porosity of the materials was included in Table 3. Interestingly, BC structures are less water vapor permeable than $\mathrm{VC}$ even when the porosity of $B C$ is higher ( $B C$ vs VC_HC6). These results can be due to the high hemicellulose content and lower crystallinity of the vegetal fiber, which both induce higher affinity to water and therefore can enhance diffusion, and also to the different dimensions of the pores in the different materials.

\section{Discussion}

The techno-economic viability of nanocellulosic materials, including $\mathrm{BC}$ and nanofibrillated $\mathrm{VC}$ depends on the performance/costs relationship, where the basic raw-material's costs and the energy intensity of the processing techniques play a crucial 


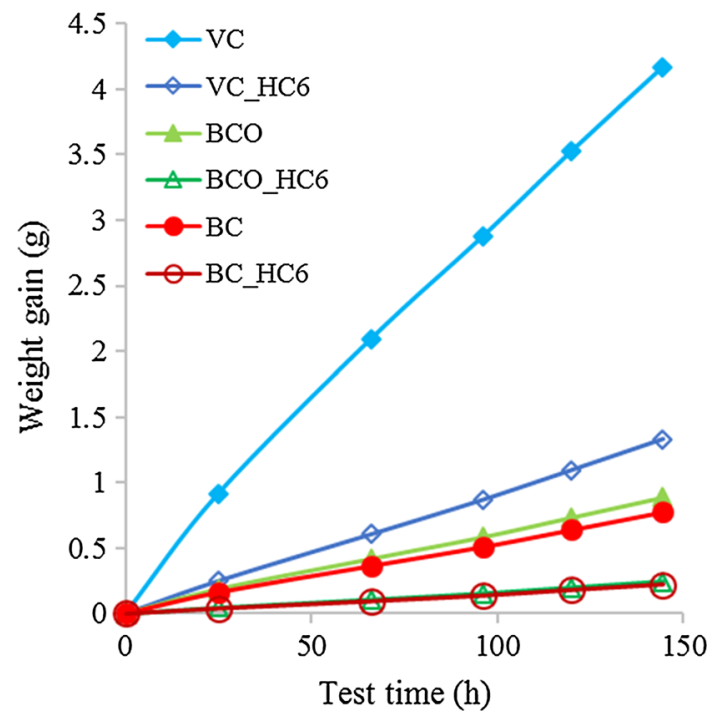

Figure 2 Transferred water vapor as a function of the test time for different cellulosic samples, with $(6$ passes $)$ and without calendering.

Table 3 WVTRs of $\mathrm{BC} / \mathrm{BCO}$ and VC films, without and with calendering (6 passes) and global porosity

\begin{tabular}{lcc}
\hline Sample & WVTR & Global porosity, \% \\
& $\left(\right.$ g.m $^{-2}$.day & \\
& 148.67 & \\
\hline VC & 46.21 & 47.5 \\
VC_HC6 & 27.12 & 9.0 \\
BC & 7.53 & 29.6 \\
BC_HC6 & 31.14 & 5.4 \\
BCO & 8.54 & 24.9 \\
BCO_HC6 & & 1.2 \\
\hline
\end{tabular}

role. To produce nanocellulose films from the corresponding suspensions, the vacuum filtration process seems to be the most promising process, as in papermaking. As expected, filtration time to make sheets from BC depends greatly on the pore size of the used filter medium; filtration time has ranged from $45 \mathrm{~min} \mathrm{[31]} \mathrm{to} 3-4 \mathrm{~h}$ [32] when fine pore size filter medium is used, but it is reduced to $8 \mathrm{~min}$ when woven filter fabric with larger openings and with variable vacuum was used for filtration [33]. In the present work, a qualitative filter paper with an average pore size of $8-11 \mu \mathrm{m}$ was used and filtration times around 6 min were required, under a vacuum of around $0.9 \mathrm{~atm}$. These filtration times are much higher than for the process of paper formation, but lower than some values reported in the literature [31-33]. In addition, the BC retention in the sheet was close to $90 \%$, which is comparable with the values reported for paper [34].
The experimental results presented in Table 2 clearly indicate that the films produced from BC/ $\mathrm{BCO}$ are much denser $\left(1.13\right.$ and $\left.1.20 \mathrm{~g} . \mathrm{cm}^{-3}\right)$ than the ones obtained from the highly beaten pulp VC fibers $\left(0.84\right.$ g.cm $\left.{ }^{-3}\right)$, which reveals a much compact and closed structure (as also observed by the lower porosity of the BC films, Table 3), in accordance with the dimension of the constitutive elements. The obtained apparent densities of BC are in good agreement with those reported by Nakagaito et al. [35] for BC films made from disintegrated BC, although they have gone through different pressing and drying processes. The values obtained for VC is also in the same magnitude of those reported by several authors [35, 36].

As it can be seen in Table 2, the non-calendered BC and $\mathrm{BCO}$ films porosities are much lower than those of the VC counterparts (29.6 and $24.9 \%$, against $47.5 \%$, respectively). After calendering, the porosity of the BC and BCO was extremely low (5.4 and $1.2 \%$, respectively). To attain similar porosities, Retegi et al. [30] applied a wet pressure of $100 \mathrm{MPa}$ on BC structures, which is certainly a more complex process than calendering. On the other hand, $\mathrm{BCO}$ films porosity seems to be more sensitive to successive calendering than BC; as observed in Table 2, the porosity decreases from 9.2 to $1.2 \%$ and 9.3 to $5.4 \%$, respectively for $\mathrm{BCO}$ and $\mathrm{BC}$, when the number of calendering passages increases from 1 to 6 passes. This behavior can tentatively be explained based on the better formation (less agglomerates) or higher nanofibrils mobility of the BCO regarding the BC. The oxidation with ozone introduces carbonyl and some carboxyl groups in cellulose [37], which should increase electrostatic repulsion between fibrils and therefore decrease flocculation [38]. Nakagaito et al. [35] have reported some extent of agglomeration in $\mathrm{BC}$ after wet disintegration. A more uniform formation leads to better structure consolidation, as the higher density suggests $\left(1.13\right.$ vs $\left.1.20 \mathrm{~g} . \mathrm{cm}^{-3}\right)$. The higher sensitivity to consolidation, however, suggests higher mobility of the oxidized nanofibrils. It should also be noted that the ozonation was carried out under vigorous agitation, which can diminish the mean BCO fibril length, which also enhances mobility in the calendering process and in the film formation itself.

Regarding the mass transfer properties, the air permeability study revealed that, while the VC films had high air permeability values, the BC films where 
completely airtight. These permeability results are also in agreement with those reported by Yousefi et al. [36]. The air barrier properties of the BC films are due to their highly dense and compact nanostructure [39, 40]. Regarding the influence of the film structure on water vapor permeability, an important property for food packaging applications, the following aspects were observed: the calendered VC (VC_HC6), exhibits higher WVTR than the before calendering $(\mathrm{BC})$, in spite of the higher porosity of the latter; the ozonated $\mathrm{BC}$ (BCO, before and after calendering) exhibits higher WVTR than the nonozonated BC (BC, before and after calendering), despite its lower porosity. Based on literature $[27,37]$, the BC submitted to ozone bleaching should have higher carbonyl and some carboxyl content than the BC, and the vegetal fibers have amorphous material (hemicelluloses). Both features lead to higher water affinity, which probably justifies the observed behavior. In fact, Nair et al. [41] have shown that hydrophobic cellulose films exhibit lower water transfer rate than the corresponding non-modified cellulose films.

Regarding transparency, another important property of films, the inverse correlation between this property and internal porosity is clear (Table 2). Lower porosity led to higher transparency, which is in accordance with Kubelka-Munk theory [20] extensively used in paper physics; a decrease in porosity means a decrease in light scattering surface area (data not shown) and consequently higher transparency. It is noticeable that the VC attains a plateau in porosity, and consequently in transparency, whereas the porosity of BC continues to decrease with calendering, and transparency as well. Moreover, in this respect, the BC films produced from $\mathrm{BC}$ submitted to ozonation attained the lowest porosity and consequently the highest transparency. The positive effect of ozone was also revealed on brightness, suggesting the presence of chromophores in the BC.

As expected, the $\mathrm{BC}$ structures are much more resistant than its VC counterparts. $B C$, the tensile index (which normalizes the load at rupture respecting the basis weight) is 146.7 and 82.8 N.m.g ${ }^{-1}$, respectively for BC and VC. The corresponding Young's modulus for $\mathrm{BC}$ and $\mathrm{VC}$ are 14.5 and $10.8 \mathrm{GPa}$, respectively. However, it is important to emphasize that both the apparent density (Table 2) and the film thickness of these materials are different.
The VC films exhibit lower apparent density, higher light scattering surface area (data not shown) and, by this way, lower inter-fiber bonded area, which, for the same intrinsic strength of the constitutive elements led to lower tensile strength index. Moreover, considering the morphological dimensions of the fibers in each case, the $\mathrm{BC}$ has certainly much higher specific surface area for inter-elements bond development, which directly affects the number of hydrogen bonds between them and, consequently, affects the mechanical properties.

The results obtained for the BC Young's modulus (14.5 to $16.7 \mathrm{GPa}$ ) are slightly lower than those reported in the literature $[10,42]$ for films obtained from never disintegrated BC membranes (15.1 to 18.0 GPa). The differences are also notorious for the tensile strength; the same authors have reported values as high as $256 \mathrm{MPa}$ for air-dry non-disintegrated films, whereas in the present study $165.8 \mathrm{MPa}$ (tensile index $146.7 \mathrm{~N} . \mathrm{m} . \mathrm{g}^{-1}$ ) was obtained for the BC films, produced after disintegration. These differences are certainly due to the disintegration process, which is responsible for the partial disruption of the originally continuous BC three-dimensional structure [36].

In order to better compare the mechanical potential between BC and VC, a normalized Young's modulus was calculated, assuming that all materials have the same density, the one of cellulose itself $\left(1.6 \mathrm{~g} . \mathrm{cm}^{-3}\right)$, which means considering a void-free material. This calculation reveals no significant differences between $\mathrm{VC}$ and BC, regarding their normalized Young's modulus, which is close to $20 \mathrm{GPa}$. The difference in the tensile index reflects mainly differences in interfiber/fibril bonded area and hydrogen bonds. The use of this normalized Younǵs modulus allows to better evaluating the effect of calendering on the strength properties of the films. This normalized Young's modulus decreases from 20.5 GPa to around $10 \mathrm{GPa}$ with calendering in the case of VC films. On the contrary, the same treatment on the BC films has only a minor effect on the normalized Young's modulus (20 vs $18 \mathrm{GPa}$ ). Interestingly, the zero-span tensile index, that accounts for the intrinsic fiber or nanofibrils tensile strength, presents similar behavior. These results suggest that under the used calendering conditions (dry state films, temperature of rolls of $100{ }^{\circ} \mathrm{C}$, and linear pressure of $120 \mathrm{kN} . \mathrm{m}^{-1}$ ) the supramolecular structure of the fiber was severely deteriorated, whereas the $\mathrm{BC}$ nanofibrils were much less affected. 
The calendering process submits the constitutive elements of the materials to very high shear stress and eventually crushing. The small dimensions of the BC nanofibrils give them more mobility in the structure and therefore it is expected that the intensity of nanofibrils damage should be lower than those experimented by the microfibrils of the VC.

Regarding ozone effect on mechanical properties, the tensile index increases with ozonation, but this may be a natural consequence of the film densification (from 1.13 to $1.20 \mathrm{~g} . \mathrm{cm}^{-3}$ ). Both normalized Younǵs modulus and dry zero-span tensile index indicated some degradation of the BC after ozone treatment, which is in agreement with a decrease in the cellulose average $\mathrm{DP}_{\mathrm{v}}$ (Table 1).

Another important feature of the data in Table 2 is the drastic decrease of the tensile strength (measured as tensile index), after calendering. The elongation at break also decreases drastically. A similar behavior was observed by Iguchi et al. [10], when the pressure applied to consolidate the BC film was increased from 49 to $1960 \mathrm{kPa}$; the authors suggested that this can be due to the introduction of defects [10]. With paper structures made with cellulosic fibers (VC), Retulainen et al. [43] have assigned this drastic decrease in tensile index to fiber debonding, due to calendering.

\section{Conclusions}

As a consequence of the $\mathrm{BC}$ films high density, its mechanical resistance is much higher than those of $\mathrm{VC}$ fibers even when they are highly beaten. Ozonation of the BC slightly improved the brightness and enhanced the films transparency, but the WVTR increased, regarding the corresponding non-ozonated $\mathrm{BC}$ films, despite the lower porosity of the BCO films. Calendering (6 passes) significantly increased film transparency and decreased the WVTR by around $70 \%$ for all the tested films, but some mechanical properties are impaired. Therefore, a compromise should be established between the benefits of ozonation and calendering, and the decrease in the mechanical performance induced by these processes.

\section{Acknowledgements}

The authors thank FCT (Fundação para a Ciência e Tecnologia) and FEDER (Fundo Europeu de
Desenvolvimento Regional) for the financial support of the project FCT PTDC/AGR-FOR/3090/2012FCOMP-01-0124-FEDER-027948 and the awarding of a research grant for Vera Costa.

\section{References}

[1] Eichhorn SJ, Dufresne A, Aranguren M, Marcovich NE, Capadona JR, Rowan SJ, Weder C, Thielemans W, Roman M, Renneckar S, Gindl W, Veigel S, Keckes J, Yano H, Abe K, Nogi M, Nakagaito AN, Mangalam A, Simonsen J, Benight AS, Bismarck A, Berglund LA, Peijs T (2010) Review: current international research into cellulose nanofibers and nanocomposites. J Mater Sci 45:1-33. doi:10. 12691/jmpc-2-1-1

[2] Castro C, Zuluaga R, Putaux JL, Caro G, Mondragon I, Ganan P (2011) Structural characterization of bacterial cellulose produced by Gluconacetobacter swingsii sp. from Colombian agroindustrial wastes. Carbohyd Polym 84:96-102

[3] Basta AH, El-Saied H (2009) Performance of improved bacterial cellulose application in the production of functional paper. J Appl Microbiol 107:2098-2107

[4] Santos SM, Carbajo JM, Gomez N, Quintana E, Ladero M, Sanchez A, Chinga-Carrasco G, Villar JC (2016) Use of bacterial cellulose in degraded paper restoration Part I: application on model papers. J Mater Sci 51(3):1541-1552. doi:10.1007/s10853-015-9476-0

[5] Siró I, Plackett D (2010) Microfibrillated cellulose and new nanocomposite materials: a review. Cellulose 17:459-494

[6] Keshk SM (2014) Bacterial cellulose production and its industrial applications. J Bioprocess Biotech 4:1-10

[7] Jonas R, Farah LF (1998) Production and application of microbial cellulose. Polym Degrad Stabil 59:101-106

[8] Czaja WK, Young DJ, Kawecki M, Brown RM (2007) The future prospects of microbial cellulose in biomedical applications. Biomacromolecules 8:1-12

[9] Yano S, Maeda H, Nakajima M, Hagiwara T, Sawaguchi T (2008) Preparation and mechanical properties of bacterial cellulose nanocomposites loaded with silica nanoparticles. Cellulose 15:111-120

[10] Iguchi M, Yamanaka S, Budhiono A (2000) Review: bacterial cellulose - a masterpiece of nature's arts. J Mater Sci 35:261-270. doi:10.1016/j.carbpol.2012.03.045

[11] Mormino R, Bungay H (2003) Composites of bacterial cellulose and paper made with a rotating disk bioreactor. Appl Microbiol Biotechnol 62:503-506

[12] Delgado-Aguilar M, González I, Pèlach MA, De La Fuente E, Negro C, Mutje P (2015) Improvement of deinked old 
newspaper/old magazine pulp suspensions by means of nanofibrillated cellulose addition. Cellulose 22:789-802

[13] Mohite BV, Patil SV (2014) A novel biomaterial: bacterial cellulose and its new era applications. Biotechnol Appl Biochem 61:101-110

[14] Charles LA, Waterhouse JF (1987) The effect of supercalendering on the strength properties of paper. Institute of Paper Chemistry. Technical Paper Series, number 244

[15] Oliveira C, Carvalho V, Domingues L, Gama FM (2015) Recombinant CBM-fusion technology-applications overview. Biotechnol Adv 33(3-4):358-369

[16] Kalia S, Dufresne A, Cherian BM, Kaith BS, Avérous L, Njuguna J (2011) Nassiopoulos (2011) cellulose-based bioand nanocomposites: a review. Int J Polym Sci 837875:1-35

[17] Lee K-Y, Tammelin T, Schulfter K, Kiiskinen H, Samela J, Bismarck A (2012) High performance cellulose nanocomposites: comparing the reinforcing ability of bacterial cellulose and nanofibrillated cellulose. Appl. Mater. Interfaces 4(8):4078-4086

[18] Dhar P, Bhardwaj U, Kumar A, Katiyar V (2014) Cellulose nanocrystals: a potential nanofiller for food packaging applications. In: Komolprasert V, Turowski P (eds) Food Additives and Packaging, vol 1162. American Chemical Society, Washington, pp 197-239

[19] Vernhes P, Bloch J, Blayo A, Pineaux P (2009) Effect of calendering on paper surface micro-structure: a multi-scale analysis. J Mater Process Technol 209:5204-5210

[20] Leskelä M (1998) Optical properties chapter 4. In: Niskanen K (ed) Paper physics (Book 16). Fapet, Helsinki

[21] Hestrin S, Schramm M (1954) Preparation of freeze-dried cells capable of polymerizing glucose to cellulose. Biochem J 58(2):345-352

[22] Sihtola H, Kyrklund B, Laamanen L, Palenius L (1963) Comparison and conversion of viscosity and DP values by different methods. Paperi Ja Puu 45(4a):225-232

[23] Segal L, Creely JJ, Martin AE Jr, Conrad CM (1962) An empirical method for estimating the degree of crystallinity of native cellulose using the X-ray diffractometer. Tex Res J 29:786-794

[24] Henriksson M, Berglund LA, Isaksson P, Lindström T, Nishino T (2008) Cellulose nanopaper structures of high toughness. Biomacromolecules 9:1579-1585

[25] Saito T, Nishiyama Y, Putaux JL, Vignon M, Isogai A (2006) Homogeneous suspensions of individualized microfibrils from TEMPO-catalyzed oxidation of native cellulose. Biomacromolecules 7(6):1687-1691

[26] González I, Alcalá M, Chinga-Carrasco G, Vilaseca F, Boufi S, Mutjé P (2014) From paper to nanopaper: evolution of mechanical and physical properties. Cellulose 21:2599-2609
[27] Pouyet F, Lachenal D, Das S, Hirat C (2013) Minimizing viscosity loss during totally chlorine-free bleaching of hardwood kraft pulp. BioResources 8(1):238-249

[28] Tsouko E, Kourmentza C, Ladakis D, Kopsahelis N, Mandala I, Papanikolaou S, Paloukis F, Alves V, Koutinas A (2015) Bacterial cellulose production from industrial waste and by-product streams. Int J Mol Sci 16(7):14832-14849

[29] Gil N, Gil C, Amaral ME, Costa AC, Duarte AP (2009) Use of enzymes to improve the refining of a bleached eucalyptus globulus kraft pulp. Biochem Eng J 46:89-95

[30] Retegi A, Gabilondo N, Peña C, Zuluaga R, Castro C, Gañan P, de la Caba K, Mondragon I (2010) Bacterial cellulose films with controlled microstructure-mechanical property relationships. Cellulose 17:661-669

[31] Sehaqui H, Liu A, Zhou Q, Berglund LA (2010) Fast preparation procedure for large, flat cellulose and cellulose/ inorganic nanopaper structure. Biomacromolecules $11: 2195-2198$

[32] Nogi M, Iwamoto S, Nakagaito AN, Yano H (2009) Optically transparent nanofiber paper. Adv Mater 21(16):15951598

[33] Zhang L, Batchelor W, Varanasi S, Tsuzuki T, Wan X (2012) Effect of cellulose nanofiber dimensions on sheet forming through filtration. Cellulose 19:561-574

[34] Biermann CJ (1996) Handbook of pulping and papermaking, 2nd edn. Academic Press, San Diego

[35] Nakagaito AN, Iwamoto S, Yano H (2005) Bacterial cellulose: the ultimate nano-scalar cellulose morphology for the production of high-strength composites. Appl Phys A 80:93-97

[36] Yousefi H, Faezipour M, Hedjazi S, Mousavi MM, Azusa M, Heidari AH (2013) Comparative study of paper and nanopaper properties prepared from bacterial cellulose nanofibers and fibers/ground cellulose nanofibers of canola straw. Ind Crop Prod 43:732-737

[37] Chirat C, Lachenal D (1994) Effect of ozone on pulp components application to bleaching of Kraft pulps. Holzforschung 48(Suppl):133-139

[38] Fall AB, Lindström SB, Sundman O, Ödberg L, Wagberg L (2011) Colloidal stability of aqueous nanofibrillated cellulose dispersions. Langmuir 27(18):11332-11338

[39] Fendler A, Villanueva MP, Giminez E, Lagarón JM (2007) Characterization of the barrier properties of composites of HDPE and purified cellulose fibers. Cellulose 14:427-438

[40] Syverud K, Stenius P (2009) Strength and barrier properties of MFC films. Cellulose 16:75-85

[41] Nair SS, Zhu JY, Deng Y, Ragauskas AJ (2014) High performance green barriers based on nanocellulose. Sustain. Chem. Process 2:23 
[42] Yamanaka S, Watanabe K, Kitamura N, Iguchi M, Mitsuhashi S, Nishi Y, Uryu M (1989) The structure and mechanical properties of sheets prepared from bacterial cellulose. J Mater Sci 24:3141-3145. doi:10.1007/BF01139032
[43] Retulainen E, Moss P, Nieminen K (1997) Effect of calendering and wetting on paper properties. J Pulp Pap Sci 23(1):J34-J39 